http://jmscr.igmpublication.org/home/ ISSN (e)-2347-176x ISSN (p) 2455-0450

crossref DOI: https://dx.doi.org/10.18535/jmscr/v9i2.48

\title{
A Clinicopathological Study of Nasal Septum Perforation in Tertiary Care Hospital, Kadapa
}

\author{
Authors \\ Dr V. Sravan Kumar ${ }^{1}$, Dr V. Umamaheswararao ${ }^{2}$ \\ ${ }^{1}$ Senior Resident in ENT, GGH, Tirupati \\ ${ }^{2}$ Senior Resident in Radiology, GGH, Tirupati
}

\begin{abstract}
Background: Septal perforation is an uncommon but bothersome illness. Treatment of nasal septal perforation mainly depends on etiology. The objectives of this study is to review the prevalence of each etiological factor causing septal perforation.

Methods: The material for this study consists of 14 patients presenting with nasal crusts, Nose bleed, Nasal discomfort to the ENT OPD, GGH, Kadapa. All information's were recorded including age, sex, address, detailed symptomatology, local examination and laboratory reports.

Results: In the present study, we registered 14 nasal septal perforation cases. Among these, 2 patients out of 14 the cause is found to be Leprosy, 1 patient the cause is found to be Atrophic rhinitis, 3patients the cause is found to be Post-operative, 1patient the cause is found to be TB, 2patients the cause is found to be Trauma, Ipatient the cause is found to be drug abuse, lpatient the cause is found to be FB, 3patients the cause is found to be unknown.

Conclusion: Though leprosy is supposed to be extinct, the Otorhinolaryngologists shall keep in mind, leprosy as a cause of pathological perforation even today.

Keywords: nasal septal perforation, granulomatous diseases of nose.
\end{abstract}

\section{Introduction}

Nasal septal perforation is through and through defect of nasal septum. Perforation of nasal septum is a curious clinical entity. The exact prevalence of septal perforations is unknown as many perforations are asymptomatic but in a general otorhinolaryngology practice, the clinician will encounter several nasal septal perforations each year.

The etiology of nasal septal perforation are trauma, granulomatous diseases, irritants and malignant diseases.

The prevalence of chronic infections producing perforations is small. In developing countries like
India specific infections such as TB, Leprosy, Syphilis are still common causes.

In many cases, it is asymptomatic but when symptomatic, patient have recurrent epistasis, nasal crusting, whistling dryness, and nasal obstruction.

Anterior perforations are generally symptomatic, while posterior perforations are asymptomatic as the inspired air is rapidly humidified by nasal mucosa.

The treatment of nasal septal perforation is symptomatic, prosthetic or surgical. Surgery may be a curative but the results are not always satisfactory as evidenced by different operative 
procedures. Prevention of septal perforation should be an important goal.

\section{Patients \& Methods}

This study is a prospective study done in GGH, Kadapa from January 2018 to December 2018. The study group consists of 14 patients attending to ENT outpatient department, with complaints of nasal crusts, nasal bleed, whistling, nasal discomfort, nose block. To establish the cause of septal perforation, A detailed history was taken principally as it is important to identify nasal trauma, cautery or surgery, substance abuse.

External and internal nasal examination was done together with nasal endoscopy. Nasal endoscopy was done to assess the margins and state of the residual septum.

Anterior Rhinoscopy and DNE Findings

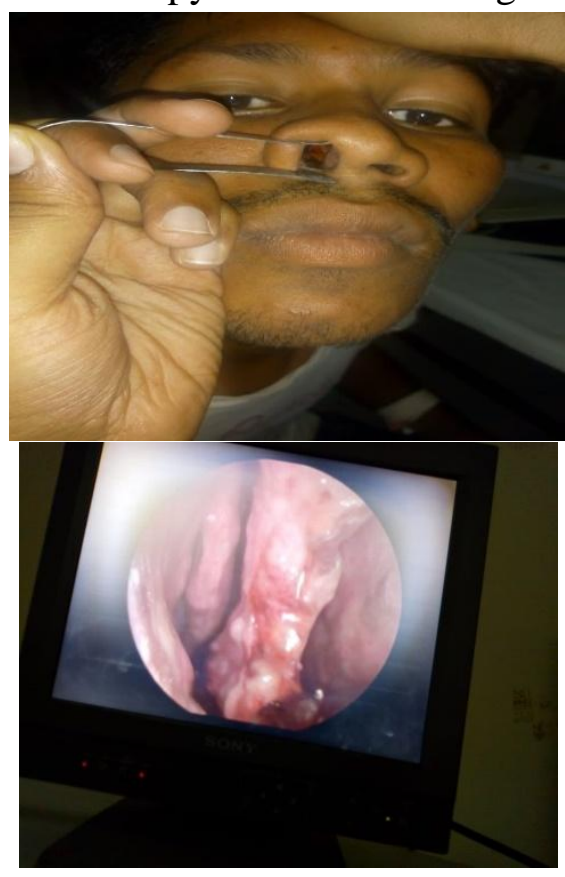

After detailed examination these patients were sent for specific investigations like:

1) Nasal smear to rule out TB / Leprosy

2) Split stain smear of ear lobule to rule out leprosy

3) Quartiferin TB gold assay test to rule out TB

4) XC- ANCA Titres- Elevated in Wegner's granulomatous

5) ACE Titres - high titre in sarcodiasis

6) VDRL- to rule out Syphilis

7) Biopsy of edges of perforation-Wegner's granulomatous

8) ESR - to rule out malignancy and chronic infections.

Even after all these investigations, we are unable to find any specific cause for septal perforation in some patients.

\section{Results}

The present study was conducted on 14 patients . A detailed history was elicited and clinical examination was done. According to history and clinical examination the patients were sent for relative laboratory investigations. The results obtained in this study were shown below.

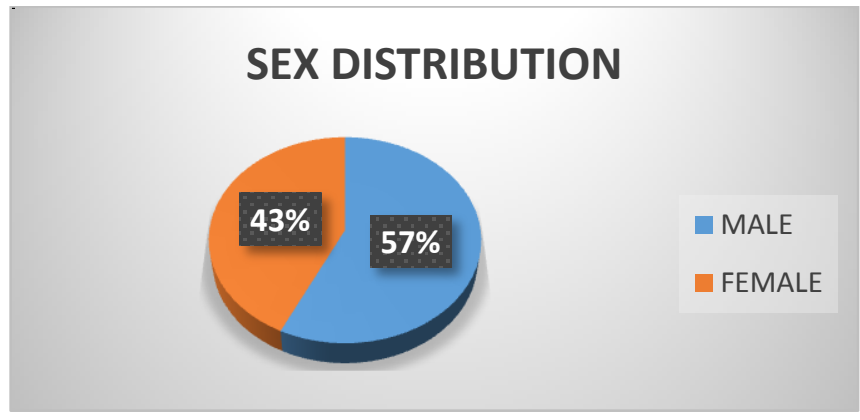

Fig.1: Sex Distribution of Cases

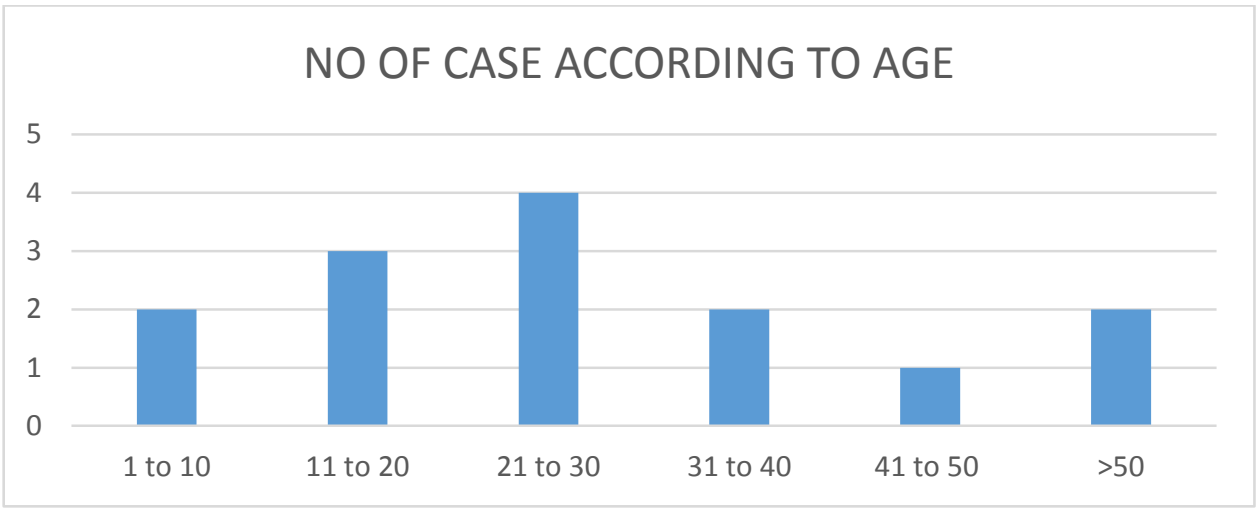

Fig. 2: Age Distribution of Cases 


\begin{tabular}{|lcc|}
\hline cause & no of cases & percentage \\
\hline leprosy & 2 & $14.2 \%$ \\
\hline atrophic rhinitis & 1 & $7.1 \%$ \\
\hline post operative & 3 & $21.4 \%$ \\
\hline tuberculosis & 1 & $7.1 \%$ \\
\hline trauma & 2 & $14.2 \%$ \\
\hline substance abuse & 1 & $7.1 \%$ \\
\hline foreign body & 1 & $7.1 \%$ \\
\hline unknown & 3 & $21.4 \%$ \\
\hline
\end{tabular}

Fig .3.Symptoms

\section{Discussion}

According to age and sex, our results show that high prevalence of nasal septal perforation is seen in young males as compared to females. This is maybe due to number of male population which undergo nasal septal correction and trauma, industrial exposure, irritant drug use.

A cross sectional study in United Kingdom done on industrial workers who are exposed to metal plating solutions conducted by questionnaire and clinical examination revealed that $14 \%$ had nasal septal perforation. Those with perforation were younger than 35 years at the time of perforation.

According to etiology, our study shows that 2 out of 14 patients, the cause of nasal septal perforations to be Lepromatous Leprosy.

In leprosy, the nose is an important portal for entry of this bacteria and is therefore frequently affected.

Depending upon the host immune response, nasal symptoms of leprosy may include epistaxis, gross nasal deformity and destruction. On nasal endoscopy friable granulomatous intranasal lesion involving the septum with associated crusting.

Leprosy which was declared eradicated in India one and a half decade ago has re-emerged in different states with high intensity.

India has the highest number of new leprosy cases in the world, followed by Brazil and Indonesia.

In our study,

2 patients out of 14 the cause is found to be Leprosy

1 patient the cause is found to be Atrophic rhinitis. 3 patients the cause is found to be Post-operative.
1 patient the cause is found to be TB

2 patients the cause is found to be Trauma

1 patient the cause is found to be drug abuse 1 patient the cause is found to be FB.

3 patients the cause is found to be unknown.

\section{Conclusion}

Though leprosy is supposed to be extinct, the Otorhinolaryngologists shall keep in mind, leprosy as a cause of pathological perforation even today.

Now a days postoperative and trauma causes of nasal septal perforation cases are reduced significantly.

\section{Acknowledgements}

We would like to thank all the study participants and authors from where we have cited the references for publication of this article.

\section{References}

1. Younger R, Blokmanis A. nasal septal perforations.j otolaryngology 1985;14: 125-31.

2. Kuriloff DB. Nasal septal perforations and nasal obstruction. Otolaryngol clin north Am 1989; 22: 333-50.

3. Brain D. septorhinoplasty : the closure of septal perforations .J otolaryngology 1980;94:495-505

4. Kridel RWH. Considerations in the etiology, treatment, and repair of septal perforations. Facial Plast Surg Clin N Am. 2004;12:435-450. doi: 10.1016/j.fsc.2004.04.014.

5. Newton JR, White PS, Lee MSW. Nasal septal perforation repair using open septoplasty and unilateral bipedicle flaps. J Laryngol Otol. 2003;117:52-55. doi: 10.1258/002221503321046649.

6. Ayshford CA, Shykhon M, Uppal HS, Wake M. Endoscopic repair of nasal septal perforation with acellular human dermal allograft and an inferior turbinate 
flap. Clin Otolaryngol. 2003;28:29-33. doi: 10.1046/j.1365-2273.2003.00654.x.

7. Masing H. Closure of a small perforation. In: Naumann HH, editor. Head and Neck Surgery. Vol. 1. Stuttgart: Georg Thieme Publisher; 1980. pp. 307-309.

8. Masing H. Plastic closure of a large septal perforation. In: Naumannn HH, editor. Head and Neck Surgery. Vol. 1. Stuttgart: Georg Thieme Publisher; 1980. pp. 359-362.

9. Friedman M, Ibrahim H, Ramakrishnan V. Inferior Turbinate Flap for Repair of Nasal Septal Perforation. Laryngoscope. 2003; 113:1425-1428. doi: 10.1097/00005537200308000-00031.

10. Woolford TJ, Jones NS. Repair of nasal septal perforations using local mucosal flaps and a composite cartilage graft. J Laryng Otol. 2001;115:22-25. doi: 10.1258/0022215011906939.

11. Schulz-Coulon H-J. Experiences with the bridge flap technique for the repair of large nasal septal perforations. Rhinology. 1994;32:25-33.

12. Brain DJ. Septorhinoplasty: the closure of septal perforations. J Laryngol Otol. 1980; 94:495-505.

13. Stoksted P, Vase P. Perforations of the nasal septum following operative procedures. Rhinology. 1978;16:123-138.

14. Schoelzel EP, Menzel ML. Nasal Sprays and Perforation of the Nasal Septum. JAMA. 1985;253: 2046 . doi: 10.1001/jama.253.14.2046b.

15. Andre RF, Lohuis PJFM, Vuyk HD. Nasal septum perforation repair using differently designed, bilateral intranasal flaps, with nonopposing suture lines. J Plast Reconstruct Aesth Surg. 2006;59:829-834. doi: 10.1016/j.bjps.2005.11.010. 